\title{
DETECTION OF ANOMALIES PRODUCED BY BURIED ARCHAEOLOGICAL STRUCTURES USING NONLINEAR PRINCIPAL COMPONENT ANALYSIS APPLIED TO AIRBORNE HYPERSPECTRAL IMAGE
}

\author{
R. M. Cavalli $^{1}$, G. A. Licciardi $^{2}$, J. Chanussot $^{2}$ \\ (1) CNR-IIA Institute of Atmospheric Pollution Research, Monterotondo, Italy \\ (2) GIPSA-Lab, Grenoble Institute of Technology, France \\ e-mail: Giorgio-Antonino.Licciardi@gipsa-lab.grenoble-inp.fr
}

\begin{abstract}
In this paper, airborne hyperspectral data have been exploited by means of Nonlinear Principal Component Analysis (NLPCA) to test their effectiveness as a tool for archaeological prospection, evaluating their potential for detecting anomalies related to buried archaeological structures. In the literature, the NLPCA was used to decorrelate the information related to a hyperspectral image. The resulting nonlinear principal components (NLPCs) contain information related to different land cover types and biophysical properties, such as vegetation coverage or soil wetness. From this point of view, NLPCA applied to airborne hyperspectral data was exploited to test their effectiveness and capability in highlighting the anomalies related to buried archaeological structures. Each component obtained from the NLPCA has been interpreted in order to assess any tonal anomalies. As a matter of a fact, since every analyzed component exhibited anomalies different in terms of size and intensity, the Separability Index (SI) was applied for measuring the tonal difference of the anomalies with respect to the surrounding area. SI has been evaluated for determining the potential of anomalies detection in each component. The airborne Multispectral Infrared and Visible Imaging Spectrometer (MIVIS) images, collected over the archaeological Park of Selinunte, were analyzed for this purpose. In this area, the presence of remains, not yet excavated, was reported by archaeologists. A previous analysis of this image, carried out to highlight the buried structures, appear to match the archaeological prospection. The results obtained by the present work demonstrate that the use of the NLPCA technique, compared to previous approaches emphasizes the ability of airborne hyperspectral images to identify buried structures. In particular, the adopted data processing flow chart (i.e. NLPCA and SI techniques, data resampling criteria and anomaly evaluations criteria) applied to MIVIS airborne hyperspectral data, collected over Selinunte Archaeological Park, highlighted the ability of the NLPCA technique in emphasizing the anomalies related to the presence of buried structure.
\end{abstract}

Index Terms - Hyperspectral image processing, nonlinear PCA, anomaly detection, archaeological prospection.

\section{INTRODUCTION}

Up to now, few remote sensing applications have been developed in discovering, monitoring, documenting and preserving cultural resources. Typically these techniques have been exploited by means of optical multispectral sensors, such as CORONA, IKONOS, Landsat Thematic Mapper (TM) and Multispectral Scanner System (MSS), Satellite Pour l'Observation de la Terre (SPOT) XI, QuickBird and Terra Advanced Spaceborne Thermal Emission and Reflection Radiometer (ASTER) within different archaeological contexts to reconstruct the ancient landscape of historical significance in many environments $[1][2][3][4][5][6][7][8][9][10][11]$. In particular, in order to detect and highlight the buried archaeological structures, the results 
presented in [12] indicate that, in general, Red, Near-infrared (NIR), Short-wave infrared (SWIR) and Thermal-infrared (TIR) regions can be exploited. However, multispectral sensors, even if they provide additional value compared to conventional aerial photographs, usually lack in spatial and spectral resolutions necessary in identifying buried archaeological structures.

The use of airborne hyperspectral sensors (i.e. Airborne Imaging Spectrometer - AISA, Airborne Hyperspectral Scanner AHS, Airborne Prism Experiment - APEX, Airborne Visible Infrared Imaging Spectrometer - AVIRIS, Compact Airborne Spectrographic Imager - CASI, Environmental Protection System- EPS-H, Digital Airborne Imaging Spectrometer - DAIS, Hyperspectral Digital Imagery Collection Experiment - HYDICE, Hyperspectral Mapper - HyMap, Multispectral Infrared and Visible Imaging Spectrometer - MIVIS, Reflective Optics System Imaging Spectrometer ROSIS, etc.) overcame the drawback of scarce spatial and spectral resolutions. As a matter of fact, remotely sensed airborne hyperspectral sensors offer a high spatial resolution related to optical characteristics and the airborne platform of the sensor and present a high spectral resolution due to the ability of hyperspectral sensors in sampling the electromagnetic spectrum with narrow consecutive spectral bands. Compared to the classical multispectral images, hyperspectral images have many advantages. In [13][14][15][16][17][18] and [19] hyperspectral images have been used to detect buried archaeological structures analyzing the anomalies stressed by the sensor. In particular, the authors highlighted that the airborne hyperspectral data are feasible for a visual interpretation and able to identify the image that bears the highest inherent archaeological information content. Therefore, the authors proved the utility of the airborne hyperspectral data as a new complementary tool in archaeological prospection [13][14][15][16][17][18]. In addition, Agapious et al. [19] reports a study that validates the use of the hyperspectral ground data in detecting buried remains.

In this context, the Italian peninsula contains a large number of ancient buried ruins consisting of either large urban centers or buildings and town-walls which have to be still fully studied and excavated. From this point of view the airborne hyperspectral image processing can be extremely effective when applied to those areas where a large number of cultural heritage resources need to be surveyed, safeguarded from grave-robbers and protected from environmental degradation, mostly due to unchecked urban development. In the literature, many techniques for the detection of anomalies have been developed [20][21][22] [23] and for the analysis of the anomalies related to buried structures [13][14][18]. However managing and processing hyperspectral images is not a simple task, mainly because of the huge number of bands. Moreover, in previous papers [13][14][15][18], an approach was based on the visual interpretation of the image to detect the buried structures and select the optimal spectral domain or the best image processing to identify the buried structures on the airborne hyperspectral images. Therefore, reducing the number of images to be visually interpreted, could speed up method to identify and highlight the buried structures on the airborne hyperspectral images, therefore to support archaeological investigations. Cavalli et al [13][14] and Bassani et al [18] introduced the selection of bands to increase the ability in detecting the buried archaeological structures and reduce the computation time. In particular, Cavalli et al [13][14] and Bassani et al [18] chose the specific spectral bands of the hyperspectral sensors to highlight the archeological buried structures, as a functions of the land cover characteristics. Therefore, Cavalli et al [13] identified a limited number of images by calculation of Principal Component Analysis (PCA) [24] and hyperspectral classifiers (i.e. Minimum Distance, MD [24] and Spectral Angle Mapper, SAM [25]) on whole data set. These limited number of synthetic data (i.e. Rule Images of MD and SAM classifiers) is the best images for detecting the buried archaeological on MIVIS data collected over the Archaeological Park of Selinunte (SW Sicily, Italy), the same data set of this work. For this purpose, many techniques have been proposed to reduce the dimensionality of the hyperspectral images preserving the inherent information content [26][27][28][29][30][31]. However, among these, the NLPCA technique, firstly introduced by Kramer in [32], presented better results in many hyperspectral applications, if compared to the other classical techniques [33][34][35][36][37]. Within this context, this paper presents the results of the NLPCA applied to MIVIS data collected over the Archaeological Park of Selinunte, for detection of anomalies related to the presence of the buried archaeological structures. The paper is structured as follows: Section 2 describes the test area of Selinuntes Archaeological Park, and deals with the MIVIS hyperspectral data set and how the images were calibrated and corrected. Section 3 addresses the methodological aspects of 
the proposed approach, describing NLPCA as a feature extraction technique and the Separability Index for detecting anomalies related to buried structures. Section 4 analyzes the results while conclusions are drawn in section 5 .

\section{AIRBORNE HYPERSPECTRAL DATA}

The concept of hyperspectral imaging, originated at the NASA Jet Propulsion Laboratory (JPL), defined the hyperspectral spectrometers like a sensor which acquires images in many contiguous spectral channels such that for each its pixel a complete spectrum can be obtained [38]. Over the past two decades, a few hyperspectral spectrometers have been built with data collected from aircraft and satellite platforms. For this study, MIVIS aircraft data (Daedalus AA5000, [39]) were processed. The MIVIS records the incoming radiation into four optical ports (see 1) covering the Visible (VIS), NIR, SWIR and TIR spectral regions with 102 channels. The MIVIS survey over the Selinunte Archaeological Park was performed by the National Research Council (CNR) on May 23, 1996, at 12.30h local time with clear sky conditions, from an altitude of $1500 \mathrm{~m}$ a.s.l. (3 m/pixel ground resolution) and the data were calibrated and corrected [40][41]. Selinunte is one of the most outstanding cultural heritage sites of Southern Italy, located along the SW coast of Sicily (Fig. 1); Selinunte was founded in the 7th century BC by colonizers who came from Megara Hyblaea (ancient Greek colony in Sicily).

The choice of a MIVIS image acquired over Selinunte was set for this study for three main reasons:

- the urban street network of Selinunte, not fully excavated at the time of the MIVIS survey, presents a sharp geometry, and the unexcavated archaeological structures are not too deeply buried (i.e.10-20cm to $1 \mathrm{~m}$ ) and have a width and length greater than two MIVIS pixels (i.e.6-9m);

- this urban street network (Fig. 2) was identified on aerophotos by Schmiedt (1957) and partly confirmed in subsequent archaeological investigations [42][43], by geomagnetic and geoelectric prospections [44];

- the same MIVIS data set over Selinunte was analyzed for identifying the features related to the ancient street network and, mainly, for evaluating airborne hyperspectral data effectiveness as a tool for the archaeological prospection [13][14].

\section{METHODS}

\subsection{Nonlinear Principal Component Analysis}

One of the main tasks of this paper is to propose a dimensionality reduction technique performed by using NLPCA, commonly referred to as nonlinear generalization of standard principal component analysis. NLPCA, is based on multi-layer perceptrons (MLP) and is commonly referred as Autoassociative Neural Network (AANN) or as autoencoder. The AANNs are NNs of a conventional type featuring feedforward connections and sigmoidal nodal transfer functions, trained by backpropagation or similar algorithms [45]. In this paper the training algorithm is the Standard Conjugated Gradient (SCG). The particular network architecture used employs three hidden layers, including an internal bottleneck layer of smaller dimension than either input or output (Fig. 3). The network is trained to perform identity mapping, where the input $X$ has to be equal to the output $X$. Training an AANN is not an easy task because of the bottleneck layer where the data have to be projected or compressed into a lower dimensional space. Since there are fewer units in the bottleneck layer than the output, the bottleneck nodes must represent or encode the information obtained from the inputs for the subsequent layers to reconstruct the input [32][45][46].

The AANN, as shown in fig. 4, can be divided into two parts: the first part represents the encoding or extraction function $F_{\text {encode }}: X \rightarrow Z$, while the second part represents the inverse function, called decoding function $F_{\text {decode }}: Z \rightarrow X$. After the training of the AANN the nonlinear principal components (NLPCs) can be extracted from the extraction subnet, while the reconstruction can be performed by the decoding subnet. The ability of the neural network to fit arbitrary nonlinear functions depends on the presence of hidden layers with nonlinear nodes. Without nonlinear nodes, the network is only capable of 
producing linear combinations of the inputs, given linear nodes in the output layer. The performance of an autoassociative neural network with only one internal layer is often no better than linear PCA. Also if the activation functions in the bottleneck nodes are sigmoidal, the projection into the sub-space will still be severely constrained. A network lacking a sufficient number of hidden layers but including sigmoidal nonlinearities in the output layer is only capable of generating multivariable sigmoidal functions, i.e., linear functions compressed into the range $(-1,1)$ by the sigmoid. For this reason, a topology with three hidden layers enables the AANN to perform non-linear mapping functions [32].

The proposed AANN algorithms can be trained by minimizing the sum-of-squares error of the form:

$$
E=\frac{1}{2} \sum_{n=1}^{N} \sum_{k=1}^{d}\left\{y_{k}\left(x^{n}\right)-x_{k}^{n}\right\}^{2}
$$

where $y_{k}(k=1,2, d)$ is the output vector. The non-linear activation function $\sigma(x)$ can be any continuous and monotonically increasing function with $\sigma(x) \rightarrow 1$ as $x \rightarrow+\infty$ and $\sigma(x) \rightarrow 0$ as $x \rightarrow-\infty$. In this paper the chosen function is the sigmoid and is applied element wise:

$$
\sigma(x)=\frac{1}{1+e^{-x}}
$$

One of the main difficulties in designing the AANN is the selection of the number of nodes in the three hidden layers and in particular in the bottleneck layer that minimizes the loss of information of the entire network. Usually, this problem can be solved by using a simple grid search algorithm that varies recursively the number of nodes of the hidden layers and evaluated the respective error and the topology presenting the lowest error is then selected. However, this approach can be useful to determine the dimension of the outer hidden layers, but considering that the nodes of the bottleneck layer should represent the nonlinear principal components, a different approach should be performed. In particular, this task can be performed by analyzing the intercorrelation between the NLPCs. In fact, it has been noted that using a number of nodes that is greater than the necessary, the information retained by the NLPCs is redundant, resulting in two or more components linearly correlated. Starting from this assumption, it is possible to perform a further grid search in order to detect the correct number of nodes that are linearly uncorrelated. This search is performed by varying iteratively the number of nodes of the bottleneck layer while the nodes of the outer hidden layers are fixed to an arbitrary value that does not change during the different iterations. A the end of each training, the correlation between the NLPCs is evaluated by means of a correlation correlation matrix. If one or more values are over a certain threshold, the number of nodes of the bottleneck layer is reduced by 1 and then the AANN is trained again with the new topology. Once detected the minimum number of uncorrelated NLPCs it is possible to perform a new grid search algorithm to select the number of nodes of the outer hidden layers in order to optimize the training error. The complete flowchart of the optimization process is reported in Fig. 5. The use of NLPCA has been proposed in literature as an effective dimensionality reduction technique applied to hyperspectral imagery [33][34][35]. Compared to linear reduction techniques, NLPCA has many advantages [37]:

- while linear approaches such as PCA, ICA or MNF, can detect and discard only linear correlations among hyperspectral bands, NLPCA permits to detect both linear and nonlinear correlations.

- in NLPCA the information content is equally distributed among the components, while in PCA, KPCA or MNF the information content is strongly unbalanced with the first component retaining most of the information.

- NLPCA does not require discarding any component to perform the dimensionality reduction, allowing NLPCA to be significantly more effective in the inverse operation of reconstruction of the original spectral information than PCA or KPCA.

Among these advantages, another important issue concerns the fact that each NLPCs is related to different types present in the 
scene. For instance, in fig. 6 all the information related to water, vegetation, sand and gravel are retained by four different NLPCs. In this way, with very few NLPCs is possible to have all the useful information for the detection of the buried archaeological structures which presence influence the growth status of the vegetation and also the humidity of the soil. Fig. 7 shows the 4 NLPCs that permitted to highlight the buried structures.

\subsection{Anomaly evaluation criteria}

In order to evaluate NLPCA capability of enhancing the anomalies related to archaeological buried structures the Separability Index (SI) [13][14][18] has been performed. Visual interpretation and knowledge of the area to which the images refer is essential to identify and detect in image the marks or tonal anomaly related to buried structures. These marks on the images are due to the different intensity of brightness related to the surrounding area; the greater the intensity of brightness related to the surrounding area and the greater the number of these pixels the more evident the anomalies. The use of visual interpretation in remote sensing for archaeological prospection is considered to be descriptive, because the visual interpretation depends on the person and his knowledge of the area. In order to fill this gap, the SI was defined to combine the visual interpretation with statistical variables related to the tonal anomalies [13][14][18]. The SI, gives an indication of the tonal difference between marks or anomalies over the archaeological buried structure (i.e. the mask called $D_{\text {archa }}$ ), and surrounding area (i.e. the mask called $D_{\text {sur }}$ ). As a matter of fact, when calculating SI visual interpretation is necessary to identify the mark related to the buried structures and the surrounding area and to draw these masks on the image. Therefore, SI measures the differences in brightness between these two masks (i.e. one related to the anomaly and another related to its surrounding area). The calculation of SI takes into consideration the difference of intensity of brightness of both masks and the number of the pixels which present this different intensity of brightness. In fact, this evaluation is performed comparing the frequency distribution of the mask of the anomaly with the related mask of the surrounding area. When, the frequency distribution of the mask of the anomaly is comparable to the frequency distribution of the mask of its surrounding area and the value of SI tends to $0 \%$, the image doesn't enhance the anomalies related to archaeological buried structures. Whereas, the frequency distribution of the mask of the anomaly is different from the frequency distribution of the mask of its surrounding area the value of SI tends to $100 \%$, the image enhances the anomalies related to archaeological buried structures.

The SI procedure is applied to each image, using the same masks, to evaluate and to rank their capability of enhancing the anomalies related to archaeological buried structures. The index is as follows:

$$
\text { S.I. }=\left(1-\frac{\int D_{\text {archa }} D_{\text {sur }} d x}{\sqrt{\int D_{\text {archa }}^{2} d x \int D_{\text {sur }}^{2} d x}}\right) X 100
$$

where $D_{\text {archa }}$ represents the frequency distribution of the digital values of the pixels belonging to the archaeological marks, while $D_{\text {sur }}$ represents the frequency distribution of the pixels selected as surrounding area. SI is, therefore, an indicator of the overlapping area of the two frequency distributions $D_{\text {archa }}$ and $D_{\text {sur }}$. According to the index definition, the SI is a parameter related to the similarity of tonality of the anomalies (i.e. pixels over the buried archaeological structures) with respect to the surrounding area [13][14][18]. Fig. 8 shows the procedure of the computation of SI.

In order to test the capability of NLPCA to enhance the anomalies related to archaeological buried structures, few archaeological areas were taken into consideration: Acropolis West, Manuzza Hill and Casa Paola (Fig. 1). In each area, groups of masks have been made in order to apply SI and to have a relevant number of groups of masks ready to test NLPCAs capability of enhancing the anomalies related to archaeological buried structures. The groups of masks made of the three archaeological areas (Fig. 2), are composed of a mask covering one the areas over buried archaeological structures, and one covering the surrounding area of the buried structures. Each group of masks is characterized by a relevant number of pixels (major then 50 pixels), represents identical land cover and identical archaeological structures (i.e. street, wall). In all MIVIS images over the 
Selinunte Archaeological Park, 14 groups of masks were made with the following characteristics:

- 6 groups of masks in Acropolis West;

- 5 groups of masks in Manuzza Hill;

- 3 groups of masks selected in Casa Paola.

Every NLPCA has been evaluated by using SI for each group of masks (i.e.14 groups). The results have been assessed according to the following methods:

- the number of groups of masks where the NLPCA obtained SI values greater than images used as data set;

- the number of groups of masks where the NLPCA obtained SI values greater than images of whole data set;

- the mean value of SI where the NLPCA obtained SI values greater than images used as data set;

- the mean value of SI where the NLPCA obtained SI values greater than images of whole data set.

These four methods for evaluation every NLPCA by using SI were called, for convenience, Evaluation 1 local, Evaluation 1 global, Evaluation 2 local and Evaluation 2 global, respectively.

\subsection{Hyperspectral data resampling criteria}

A lot of input datasets, with different spatial and spectral resizes, have been performed in order to better test NLPCA capability of enhancing the anomalies related to archaeological buried structures. The original spatial size of the MIVIS dataset over the Selinunte Archaeological Park is an image of $1001 \times 620$ pixels, highlighted with a green square in Fig. 1, while the spatial resize, 500x480 pixels referred to the red square in Fig. 1, was chosen in order to concentrate the statistic information only on the investigated area. The original spectral of the MIVIS dataset [13] is an image composed by 136 bands (102 MIVIS bands and 34 synthetic bands obtained by multispectral elaborations, that spans from PCA to Apparent thermal Inertia (ATI) [47][48], and hyperspectral classifiers, that spans from MD to SAM). As for the spectral reductions were performed on one hand excluding channels with SNR values lower than 40 (i.e. 126, 102 and 92 bands) and 35 (66 bands) from original spectral of the MIVIS dataset with or without the synthetic bands. On the other hand some bands were discarded considering ground truth SI values greater than 75\% obtained separately over the different archaeological areas and SI values greater than 80 and $85 \%$ obtained over whole archaeological areas. For instance, on the Casa Paola site only 39 bands, on the Acropolis West site only 33 bands and on the Manuzza Hill only 32 bands were selected according to the 75\% SI value constraint. While, dataset with 26 and 12 bands were chosen according to the 80 and $85 \%$ SI value thresholds respectively. These values of SI have been achieved over more than 7 groups of masks, regardless of archaeological areas.

According to the spectral and spatial resizes applied to the original MIVIS dataset 12 further datasets have been produced, a full description of the different datasets is reported in Tables 2-3. For each these NLPCA, the SI [13][14][18] have been elaborated to evaluate their capability.

\section{DATA ANALYSIS}

For each of the 12 different datasets produced, an iterative training of the AANN was performed using a scaled conjugate gradient algorithm [49] to detect the best topology representing the inherent information. Moreover, for sake of comparison, NLPCs having both linear and nonlinear outputs have been produced from some of those datasets, resulting in 19 results to be analyzed, as reported in Table 4. This procedure was necessary because in the AANN, the activation level of an output unit is a function of the net input to it and the units activation function. As described before, it has been used a conventional 
sigmoid activation function (Equation 2). Scope of this activation function is to force the output from a unit towards 0 or 1 [50]. Although this was useful in training the network, it provides a distinctly non-linear measure of the distribution of the values. The output unit activation levels could be re-scaled to remove the bias towards very low and high values imposed by the unit activation function. This was achieved here by switching the output unit activation function, after training, to a linear function [51].

For each group of masks (i.e.14 groups), Separability Index [13][14][18] have been carried out to evaluate the potentiality of NLPCA to emphasize the anomalies related to the presence of buried structures. The evaluation of the potentiality of NLPCA to produce features able to emphasize the anomalies related to the presence of buried structures, was carried out following four described methods (i.e. Evaluation 1 local, Evaluation 1 global, Evaluation 2 local and Evaluation 2 global), reported in Table 4. The scheme in Fig. 9 shows the complete evaluation process.

The best results of Evaluation 1 local and 1 global have been obtained with 10 NLPCs obtained with a nonlinear output function, produced by input data selected according to the 75\% SI value constraint. While, the best results of Evaluation 2 local and global have been obtained with 3 NLPCs (non linear output function) produced by input data selected according to the 35 SNR threshold. Therefore, the best input data were 32, 33, 39 and 66 bands. The lower values of Evaluation 1 and 2, local and global, have been obtained with NLPCs produced by input data set with spectral size more than 92 bands and less than 26 bands. The same behavior shows the results of Evaluation 1 local and global with the exception of NLPCs (non linear output function) produced by the input data of 12 and 26 bands.

Theses results demonstrate the potentialities of the NLPCA to extract the intrinsic information from the data and to highlight the anomalies present in the image. Another important results is related to the activation function of the output layer of the AANN. In fact, it has been noted that the best results have been obtained using a nonlinear output activation function instead of a linear one. This could be explained by analyzing the frequency distributions of two NLPCs sets obtained with a linear and a nonlinear activation function in the output nodes, respectively (Fig. 10). With a linear output the presence of very low and high values tends to compress the frequency distribution in the center of the curve. On the other hand the sigmoid activation function compresses the very low and high values, avoiding the alteration of the distribution curve around the median value. This means that the linear activation function tends to highlight possible anomalies in the border of the histogram, while the sigmoid function enhance the anomalies close to the center of the distribution curve.

In general it can be noted that the NLPCA method obtains good results for adequate input datasets spectral resized (i.e. number of bands less than 92 and more than 26 bands). In particular, two criteria adopted for resampling the input dataset obtained good results; the selection of the input bands using SI values identified a greater number of NLPCA with the highest values of Evaluation 1 local and global methods, while the selection of the input bands using SNR identified a few NLPCA with the highest values of Evaluation 2 local and global methods. Analyzing the number of zones where the SI values obtained with the NLPCA method is higher than the threshold one, it can be noted that the spatial resize together with adequate spectral resized permitted to have better results in both local and global Evaluation 1 and 2 methods.

On the other hand, analyzing the spectral resize, it is possible to detect an increasing trend in the number of detected zones as the number of bands decrease. However this trend presents a lower bound where the datasets composed by too few bands are not be able to retain all the necessary information for an acceptable result. This is particularly evident with the datasets composed by 12 and 26 input bands where the NLPCs obtained were not able to emphasize the anomalies in the image related to the buried structures. A similar consideration can be made to the upper bound of this trend. In fact, adding too much redundant information, that can be derived from to the input image may negatively influence the results, as it can be seen in the 136 and 126 datasets obtained with synthetic bands (i.e. ATI, PCA and the rule images of MD to SAM). It is important to note that the previous work, on the same image, used these synthetic images to reduce the data set and to obtain the best values of SI [13][14][18]. These values of SI have been compared with the results of the proposed method. As a matter of a fact, two methods used to evaluate every NLPCA (i.e. Evaluation 1 global and Evaluation 2 global) have been taken into considerations 
and compared the results of whole data set, (i.e. MIVIS bands, ATI, PCA and the rule images of the MD and SAM).

Aside from these considerations, the main issue that can be taken into account is the fact that even if the bands selection was performed on a local basis, good results have been obtained also on the other areas. As a matter of fact, the capability of NLPCA to emphasize the anomalies is independent of the archaeological area used as a threshold to select the input bands. In particular, the anomalies, obtained with NLPCs produced by the input data set of 39 bands selected according to the $75 \%$ SI value constraint on the Casa Paola site, have been stretched over all archaeological areas and have been emphasized on the Casa Paola site. The same results have been obtain with NLPCs produced by the input data set of 33 and 32 bands selected on the Acropoli west site and Manuzza hill, respectively. This outcome suggests that the anomalies of the spectral characteristics of soil and vegetation, are emphasized by the NLPCs, and this is particularly clear on the three considered zones that having similar characteristics should present the same type of anomalies related to buried structures. In particular, an analysis of the spectral range of the best input datasets of 32, 33, 39 and 66 bands, is possible to note that they fall into four spectral regions included (i.e. VIS, NIR, SWIR and TIR), as depicted in Table 5. This confirms the assumption that the anomalies produced by buried structures influences mainly the grown of vegetation and also the humidity of the soil, as also pointed out in [13].

In a general way it is possible to affirm that these results demonstrates that the use of the NLPCA technique, compared to previous approaches is able to better emphasizes the ability of hyperspectral images to retrieve buried structures and can be effectively employed for the retrieval of buried archaeological structures.

\section{CONCLUSIONS}

In this paper a novel approach, for the retrieval of buried archaeological structures based on the use of Nonlinear Principal Component Analysis applied to airborne hyperspectral image, has been presented. The proposed method extracted the intrinsic information of the hyperspectral dataset and transformed into a few principal components that are nonlinearly uncorrelated. Each nonlinear component seems to retain information about different biophysical properties present in the airborne hyperspec-

tral image. This permitted the nonlinear principal components to be used to highlight and, consequently, detect the anomalies that may indicate the presence of buried structures. In particular, the presence of these structures can be related to anomalies in biophysical information, such as the difference in vegetation growth and soil humidity. The assessment of the capability of NLPCA to detect these anomalies has been carried out by analyzing several datasets obtained applying the NLPCA method to different subsets of an airborne MIVIS image of the archaeological Park of Selinunte. The obtained results show that, independently from the selected dataset, the best results are obtained when the features selected to compose a dataset fall into four main spectral regions (i.e. VIS, NIR, SWIR and TIR), that are the most sensitive in terms of vegetation growth and soil humidity. As a matter of fact, the spectral range of the best input datasets (i.e. 32, 33, 39 and 66 bands) covered four spectral regions. Therefore, two criteria adopted for resembling the input bands obtained good results; the selection of the bands containing most archaeological content (i.e. the highest value of SI) identified a greater number of NLPCA with SI values higher than the images used as dataset and than the images of the whole dataset (i.e. Evaluation 1 local and global methods); while the selection of the bands with less SNR identified a few NLPCA with a greater value of SI than the images used as dataset and than the images of the whole dataset (i.e. Evaluation 2 local and global methods). A further analysis has been carried out by adding redundant information to the spectral bands that can better highlight the anomalies in the image, such as whole dataset and synthetic bands (i.e. MD and SAM rule images, PCA and ATI). The experiments demonstrated that this approach doesnt lead to an increase in the number of detected areas. Another important result regards the type of activation function used in the output layer of the AANN. In particular, it has been noted that a nonlinear function, such as a sigmoid one, permits to better enhance the anomalies related to the buried structures in the image.

As a final remark, the data processing flow chart, comprising NLPCA and SI techniques, data resampling criteria and anomaly evaluations criteria, applied to MIVIS airborne hyperspectral data collected over Selinunte Archaeological Park, is better able to emphasize the anomalies that are related to the presence of buried structures, when compared to previous approaches (i.e. 
MD and SAM rule images). Consequently, the use of the NLPCA approach as a preprocessing technique could be considered as a useful instrument supporting archaeological investigation. Future studies will focus on the ability of the NLPCA to retrieve buried structures in images presenting different types of anomalies.

\section{REFERENCES}

[1] I. Scollar, A. Tabbagh, A. Hesse, and I. Herzog, “A archaeological prospecting and remote sensing," Cambridge University Press, 1990.

[2] I. Shennan and D.N.M. Donoghue, "Remote sensing in archaeological research," Proceedings of the British Academy, 1992.

[3] M.J.F. Fowler, "A high-resolution satellite image of archaeological features of the south of stonehenge," International Journal Remote Sensing, vol. 22, no. 7, pp. 1167-1171, 2001.

[4] E. Ben-Dor, M. Kochavi, L. Vinizki, M. Shionim, and J. Portugali, "Detection of buried ancient walls using airborne thermal video radiometry," International Journal Remote Sensing, vol. 22, no. 18, pp. 3689-3702, 2001.

[5] B. Aminzadeh and F. Samani, "Identifying the boundaries of the historical site of the persepoli using remote sensing," Remote Sensing of Environment, vol. 102, pp. 52-62, 2006.

[6] M. Altaweel, "The use of aster satellite imagery in archaeological contexts," Archaeol. Prospect, vol. 12, pp. 151-166, 2005.

[7] A. Beck, G. Philip, and M. Abdulkarim D. Donoghue, "Evaluation of corona and ikonos high resolution satellite imagery for archaeological prospection in western syria,” Antiquity, vol. 81, pp. 161-175, 2007.

[8] V. De Laet, E. Paulissen, and M. Waelkens, "Methods for the extraction of archaeological features from very highresolution ikonos-2 remote sensing imagery, hisar (southwest turkey)," J. Archaeol. Sci., vol. 34, pp. 830-841, 2007.

[9] R. Goossens, A. De Wulf, J. Bourgeois, W. Gheyle, and T. Willems, "Satellite imagery and archaeology: the example of corona in the altai mountains," J. Archaeol. Sci., vol. 33, pp. 745-755, 2006.

[10] Y. Backe Forsberg, H. Holmgren, A. Lanorte, N. Lasaponara, and N.Masini, "Airborne and satellite multispectral imagery at the etruscan site of san giovenale, blera (lazio) preliminary results," Advances in remote sensing for archaeology and cultural heritage management. Aracne, Roma, 2008.

[11] Lin A.Y., Novo A., Shay Har-Noy, Ricklin N.D., and Stamatiou K., "Combining geoeye-1 satellite remote sensing, uav aerial imaging, and geophysical surveys in anomaly detection applied to archaeology," IEEE Journal of Selected Topics in Applied Earth Observations and Remote Sensing, vol. 4, no. 4, pp. 870-876, 2011.

[12] D. Powlesland, J. Lyall, and D. Donoghue, "Enhancing the record through remote sensing: the application and integration of multi-sensor, noninvasive remote sensing techniques for the enhancement of the sites and monuments record," Heslerton Parish Project, 2, Internet Archaeology, North Yorkshire, England, 1997.

[13] R. M. Cavalli, F. Colosi, A. Palombo, S. Pignatti, and M. Poscolieri, "Remote hyperspectral imagery as a support to archaeological prospection,” Journal Of Cultural Heritage, vol. 8, pp. 272-283, 2007.

[14] R. M. Cavalli, F. Colosi, and S. Pignatti., "Optimal spectral domain selection for maximizing archaeological signatures: Italy case studies," Sensors, vol. 9, pp. 1754-67, 2009. 
[15] P. Merola, D. Guglietta, S. Sampietri, and A. Allegrini, "Lylibaeum reconstruction by remotely data. in remote sensing for archaeology and cultural heritage management," Proceedings of the 1st Int. EARSeL Workshop, Rome, Italy, 2008, pp. 71-74, 2008.

[16] A. Rowlands and A. Sarris, "Detection of exposed and subsurface archaeological remains using multi-sensor remote sensing," Journal of Archaeological Science, vol. 34, no. 5, pp. 795-803, 2007.

[17] D. Alexakis, D. Alexakis, A. Sarris, T. Astaras, and K. Albanakis, "Detection of neolithic settlements in thessaly (greece) through multispectral and hyperspectral satellite imagery.," Sensors, vol. 9, pp. 1167-1187, 2009.

[18] C. Bassani, R. M. Cavalli, R. Goffredo, A. Palombo, S. Pascucci, and S. Pignatti, "Specific spectral bands for different land cover contexts to improve the efficiency of remote sensing archaeological prospection: The arpi case study," Journal of Cultural Heritage, vol. 10, no. 1, pp. 41-48, 2009.

[19] A. Agapiou, D. Hadjimitsis, A. Sarris, K. Themistocleous, and G. Papadavid, "Hyperspectral ground truth data for the detection of buried architectural remains," Lecture Notes in Computer Science, vol. 6436, pp. 318-331, 2010.

[20] D. Manolakis, C. Siracusa, and G. Shaw, "Hyperspectral subpixel target detection using the linear mixing model," Geoscience and Remote Sensing, IEEE Transactions on, vol. 39, no. 7, pp. 1392 -1409, 2001.

[21] L.M. Bruce, C. Morgan, and S. Larsen, "Automated detection of subpixel hyperspectral targets with continuous and discrete wavelet transforms," Geoscience and Remote Sensing, IEEE Transactions on, vol. 39, no. 10, pp. 2217 -2226, 2001.

[22] J.E. Fowler and Qian Du, "Anomaly detection and reconstruction from random projections," Image Processing, IEEE Transactions on, vol. 21, no. 1, pp. $184-195,2012$.

[23] L. Zhang, B. Du, and Zhong Y., "Anomaly hybrid detectors based on selective endmembers," IEEE Transactions on Geoscience and Remote Sensing, vol. 48, no. 6, pp. 2633-2646, 2010.

[24] J.A. Richards, "Remote sensing digital image analysis," Springer-Verlag, Berlin, p. 240, 1999.

[25] F.A. Kruse, A. B. Lefkoff, J. B. Boardman, K. B. Heidebrecht, A. T. Shapiro, P. J. Barloon, and A. F. H. Goetz, "The spectral image processing system (sips) - interactive visualization and analysis of imaging spectrometer data," Remote Sensing of Environment, Special issue on AVIRIS, vol. 44, pp. 145-163, 1993.

[26] C. Jutten and J. Hérault, "Blind separation of sources, part i: an adaptive algorithm based on neuromimetic architecture," Signal Processing, vol. 24, pp. 1-10, 1991.

[27] A. Hyvarinen and E. Oja, "Independent component analysis: Algorithms and applications," Neural Networks, vol. 13, no. 4-5, pp. 411-430, 2000.

[28] A. A. Green, M. Berman, P. Switzer, and M. D. Craig, "A transformation for ordering multispectral data in terms of image quality with implications for noise removal," IEEE Trans. Geosci. Remote Sens., vol. 26, no. 1, pp. 65-74, 1988.

[29] P. Mitra, C. A. Murthy, and S. K. Pal, "Unsupervised feature selection using feature similarity," IEEE Trans. Pattern Anal. Mach. Intell., vol. 24, no. 3, pp. 301-312, 2002.

[30] A. Plaza, P. Martinez, J. Plaza, and R. Perez, "Dimensionality reduction and classification of hyperspectral image data using sequences of extended morphological transformations," IEEE Trans. Geosci. Remote Sens., vol. 43, no. 3, pp. 466-479, 2005. 
[31] R. Muller, S. Mika, G. Ratsch, K. Tsuda, and B. Scholkopf, "An introduction to kernel-based learning algorithms," IEEE Trans. Neural Networks, vol. 12, no. 2, pp. 181-202, 2001.

[32] M. A. Kramer, "Nonlinear principal component analysis using autoassociative neural networks," AIChE J., vol. 37, pp. 233-243, 1991.

[33] G. Licciardi and F. Del Frate, "Pixel unmixing in hyperspectral data by means of neural networks," Geoscience and Remote Sensing, IEEE Transactions on, vol. 49, pp. 4163-4172, 2011.

[34] G. Licciardi, F. Del Frate, and R. Duca, "Feature reduction of hyperspectral data using autoassociative neural networks algorithms," Geoscience and Remote Sensing Symposium,2009 IEEE International,IGARSS 2009, vol. 1, pp. 176-179, 2009.

[35] G. Licciardi, F. Del Frate, G. Schiavon, and D. Solimini, "Dimensionality reduction of hyperspectral data: Assessing the performance of autoassociative neural networks," Geoscience and Remote Sensing Symposium,2010 IEEE International,IGARSS 2010, pp. 4377-4380, 2010.

[36] G. Licciardi, "Neural network architectures for information extraction from hyper-spectral images," Ph.D. Thesis, 2010.

[37] G. Licciardi, P. R. Marpu, J. Chanussot, and J. A. Benediktsson, "Linear versus nonlinear pca for the classification of hyperspectral data based on the extended morphological profiles," Geoscience and Remote Sensing Letters, IEEE, vol. 9 , no. 3, 2011.

[38] A. F. H. Goetz, G. Vane, J. Solomon, and B. N. Rock, "Imaging spectrometry for earth remote sensing," Science, vol. 228, pp. 1147-1153, 1985.

[39] R. Bianchi, R. M. Cavalli, C. M. Marino, and S. Pignatti, "Mivis airborne hyperspectral remote sensing in europe," International Symposium on Spectral Sensing Research - ISSSR Melbourne, 1995.

[40] C. Bassani, R. M. Cavalli, F. Madonna, A. Palombo, and S. Pignatti, "Laboratory activity for a new procedure of mivis calibration and relative validation with test data," Annals of Geophysics, vol. 49, pp. 45-56, 2006.

[41] C. Bassani, R. M. Cavalli, and S. Pignatti, "Aerosol optical retrieval and surface reflectance from airborne remote sensing data over land," Sensors, vol. 10, pp. 6421-6438, 2010.

[42] A. Rallo, "Scavi e ricerche nella citta" antica di selinunte. relazione preliminare," Kokalos, vol. 22-23, pp. 720-723, 1976-77.

[43] A. Rallo, “Nuovi aspetti dell'urbanistica selinuntina,” ASAtene, vol. 46, pp. 81-96, 1984.

[44] D. Mertens, “I. selinus, die stadt und ihre mauern, verlag philipp von zaberm," Mainz am Rein, Germany, 2003.

[45] C. Bishop, "Neural networks for pattern recognition,” Oxford Univ. Press, London, U.K., 1995.

[46] M. Scholz, F. Kaplan, L. Guy, J. Kopka, and J. Selbig, "Non-linear pca: a missing data approach,” Bioinformatics, vol. 21, pp. 3887-3895, 2005.

[47] E. Ben-Dor, J. Portugali, M. Kochavi, M. Shimoni, and L. Vinitzky, "Airborne thermal video radiometry and excavation planning at tel leviah, golan heights, israel," Journal of Field Archaeology, vol. 26, no. 2, pp. 117-127, 1999.

[48] A.B. Kahle, "Surface emittance, temperature, and thermal inertia derived from thermal infrared multispectral scanner (tims) data for death valley, california," Geophysics, vol. 52, no. 7, pp. 858-874, 1987. 
[49] M. F. Moller, "A scaled conjugate gradient algorithm for fast supervised learning," Neural Networks, vol. 6, pp. 525-533, 1993.

[50] I. Aleksander and H. Morton, "An introduction to neural computing," Chapman and Hall, London, 1990.

[51] G. M. Foody, "Relating the land-cover composition of mixed pixels to artificial neural network classification output," Photogramm. Eng. Remote Sens., vol. 62, no. 5, pp. 491-499, 1996.

\begin{tabular}{ccccc}
\hline $\begin{array}{c}\text { Spectral } \\
\text { region }\end{array}$ & $\begin{array}{c}\text { Spectral } \\
\text { resolution }(\mu m)\end{array}$ & $\begin{array}{c}\text { Spectral } \\
\text { range }(\mu \mathrm{m})\end{array}$ & $\begin{array}{c}\text { Spatial } \\
\text { resolution }(\mathrm{m})\end{array}$ & $\begin{array}{c}\text { IFOV } \\
(\mathrm{deg})\end{array}$ \\
\hline VIS (20 ch.) & 0.02 & $0.43-0.83$ & & \\
NIR (8 ch.) & 0.05 & $1.15-1.55$ & $\cong 3$ & 0.115 \\
SWIR (64 ch.) & 0.09 & $1.983-2.478$ & & \\
TIR (10 ch.) & $0.34-0.54$ & $8.180-12.700$ & & \\
\hline
\end{tabular}

Table 1. Characteristics of the MIVIS sensor used for this study.

\begin{tabular}{ccc}
\hline Spatial size & Spectral size & MIVIS constraint \\
\hline FR & 136 & Whole \\
FR & 126 & $<$ SNR 40\% \\
RR & 126 & $<$ SNR 40\% \\
RR & 102 & Whole \\
RR & 102 & $<$ SNR 40\% \\
RR & 92 & $<$ SNR 40\% \\
RR & 66 & $<$ SNR 35\% \\
RR & 39 & $>$ SI 75\% on Paola \\
RR & 33 & $>$ SI 75\% on AW \\
RR & 32 & $>$ SI 75\% on MH \\
RR & 26 & $>$ SI $80 \%$ \\
RR & 12 & $>$ SI $85 \%$ \\
\hline
\end{tabular}

Table 2. Description of the constraint method used to select the subset of bands composing the 12 datasets produced from the original image. $(\mathrm{FR}=1001 \mathrm{X} 620$ pixels, $\mathrm{RR}=500 \mathrm{X} 480$ pixels $)$ 


\begin{tabular}{|c|c|c|c|c|c|c|c|c|}
\hline \multirow{2}{*}{$\begin{array}{c}\text { Spatial } \\
\text { size }\end{array}$} & \multirow{2}{*}{$\begin{array}{l}\text { Spectral } \\
\text { size }\end{array}$} & \multicolumn{4}{|c|}{ Spectral coverage } & \multicolumn{3}{|c|}{ Synthetic features } \\
\hline & & VIS & NIR & SWIR & TIR & PCA & & Rules \\
\hline FR & 136 & $0.44-0.82$ & $1.18-1.53$ & $1.99-2.47$ & $8.39-12.47$ & VIS-NIR-SWIR-TIR & ATI & SAM - MD \\
\hline FR & 126 & $0.44-0.82$ & $1.18-1.53$ & $1.99-2.41$ & $8.39-12.47$ & VIS-NIR-SWIR-TIR & ATI & SAM - MD \\
\hline $\mathrm{RR}$ & 126 & $0.44-0.82$ & $1.18-1.53$ & $1.99-2.41$ & $8.39-12.47$ & VIS-NIR-SWIR-TIR & ATI & SAM - MD \\
\hline $\mathrm{RR}$ & 102 & $0.44-0.82$ & $1.18-1.53$ & $1.99-2.47$ & $8.39-12.47$ & & & \\
\hline $\mathrm{RR}$ & 102 & $0.44-0.82$ & $1.18-1.53$ & $1.99-2.41$ & $8.39-12.47$ & VIS-NIR & & \\
\hline $\mathrm{RR}$ & 92 & $0.44-0.82$ & $1.18-1.53$ & $1.99-2.41$ & $8.39-12.47$ & & & \\
\hline $\mathrm{RR}$ & 66 & $0.44-0.82$ & $1.18-1.53$ & $1.99-2.26$ & $8.39-9.59$ & & & \\
\hline $\mathrm{RR}$ & 39 & $0.70-0.82$ & $1.43-1.53$ & $1.99-2.21$ & $8.39-11.95$ & & & \\
\hline $\mathrm{RR}$ & 33 & 0.46 & $1.48-1.53$ & $1.99-2.22$ & $8.39-11.45$ & & & \\
\hline $\mathrm{RR}$ & 32 & $0.70-0.82$ & 1.48 & $2.01-2.22$ & $8.79-11.45$ & & & \\
\hline $\mathrm{RR}$ & 26 & $0.72-0.82$ & 1.53 & $1.99-2.10$ & $8.39-11.45$ & & & \\
\hline $\mathrm{RR}$ & 12 & $0.74-0.82$ & 1.53 & $1.99-2.05$ & 9.22 & & & \\
\hline
\end{tabular}

Table 3. Spectral/spatial characteristics of the 12 datasets produced from the original image. $(\mathrm{FR}=1001 \mathrm{X} 620$ pixels, $\mathrm{RR}=500 \mathrm{X} 480$ pixels $)$

\begin{tabular}{cccccccc}
\hline $\begin{array}{c}\text { Spatial size } \\
\text { (Pixel) }\end{array}$ & Spectral size & NLPCs & Output & \multicolumn{2}{c}{ Evaluation 1 } & \multicolumn{2}{c}{ Evaluation 2 } \\
local & global & local & global \\
\hline \hline $500 X 480$ & 12 (MIVIS) & 10 & linear & $2 / 14$ & $1 / 14$ & 2 & 3 \\
$500 X 480$ & 12 (MIVIS) & 10 & non linear & $2 / 14$ & $2 / 14$ & 19 & 14 \\
\hline $500 X 480$ & 26 (MIVIS) & 10 & linear & $2 / 14$ & $0 / 14$ & 2 & 0 \\
$500 X 480$ & 26 (MIVIS) & 10 & non linear & $5 / 14$ & $2 / 14$ & 5 & 3 \\
\hline $500 X 480$ & 32 (MIVIS - SI $>75 \%$ on Man) & 10 & linear & $13 / 14$ & $8 / 14$ & 7 & 3 \\
$500 X 480$ & 32 (MIVIS - SI $>75 \%$ on Man) & 10 & non linear & $13 / 14$ & $10 / 14$ & 11 & 5 \\
\hline $500 X 480$ & 33 (MIVIS - SI $>75 \%$ on AW) & 10 & linear & $11 / 14$ & $5 / 14$ & 12 & 7 \\
$500 X 480$ & 33 (MIVIS - SI $>75 \%$ on AW) & 10 & non linear & $11 / 14$ & $9 / 14$ & 25 & 19 \\
\hline $500 X 480$ & 39 (MIVIS - SI $>75 \%$ on Paola) & 10 & linear & $10 / 14$ & $5 / 14$ & 6 & 2 \\
$500 X 480$ & 39 (MIVIS - SI $>75 \%$ on Paola) & 10 & non linear & $13 / 14$ & $12 / 14$ & 13 & 8 \\
\hline $500 X 480$ & 66 (MIVIS) & 3 & non linear & $6 / 14$ & $6 / 14$ & 36 & 30 \\
\hline $500 X 480$ & 92 (MIVIS - SNR) & 10 & linear & $8 / 14$ & $8 / 14$ & 9 & 3 \\
$500 X 480$ & 92 (MIVIS - SNR) & 10 & non linear & $12 / 14$ & $6 / 14$ & 15 & 27 \\
\hline $500 X 480$ & 102 (MIVIS - Elab.) & 5 & linear & $1 / 14$ & $1 / 14$ & 1 & 1 \\
\hline $500 X 480$ & 102 (MIVIS) & 10 & linear & $1 / 14$ & $1 / 14$ & 0 & 4 \\
$500 X 480$ & 102 (MIVIS) & 10 & non linear & $0 / 14$ & $1 / 14$ & 4 & 4 \\
\hline $500 X 480$ & 126 (MIVIS - Elab.) & 10 & non linear & $0 / 14$ & $0 / 14$ & 0 & 0 \\
\hline $1001 X 620$ & 126 (MIVIS - Elab.) & 10 & non linear & $0 / 14$ & $0 / 14$ & 0 & 0 \\
\hline $1001 X 620$ & 136 (MIVIS - Elab.) & 10 & non linear & $0 / 14$ & $0 / 14$ & 0 & 0 \\
\hline
\end{tabular}

Table 4. The results of evaluation of the potentiality of NLPC following Evaluation 1 local, Evaluation 1 global, Evaluation 2 local and Evaluation 2 global methods. The first column describes spatial size of the input data, the second column shows spectral size of the input data and the third column summarizes selection criteria of the bands. The quarter and fifth columns summarize NLPC characteristics. At the last four columns summarize the results of Evaluation 1 local, Evaluation 1 global, Evaluation 2 local and Evaluation 2 global methods for each NLPC. 


\begin{tabular}{|c|c|c|c|c|}
\hline \multirow[t]{2}{*}{ Region } & 66 bands & 39 bands & 33 bands & 32 bands \\
\hline & \multicolumn{4}{|c|}{ Spectral coverage $(\mu \mathrm{m})$} \\
\hline VIS & $0.44-0.82$ & $0.70-0.82$ & 0.46 & $0.70-0.82$ \\
\hline NIR & $1.18-1.53$ & $1.43-1.53$ & $1.48-1.53$ & 1.48 \\
\hline SWIR & $1.99-2.26$ & $1.99-2.21$ & $1.99-2.22$ & $2.01-2.22$ \\
\hline TIR & $8.39-9.59$ & $8.39-11.95$ & $8.39-11.45$ & $8.79-11.45$ \\
\hline
\end{tabular}

Table 5. Spectral range of the best input datasets (i.e. 32, 33, 39 and 66 bands).

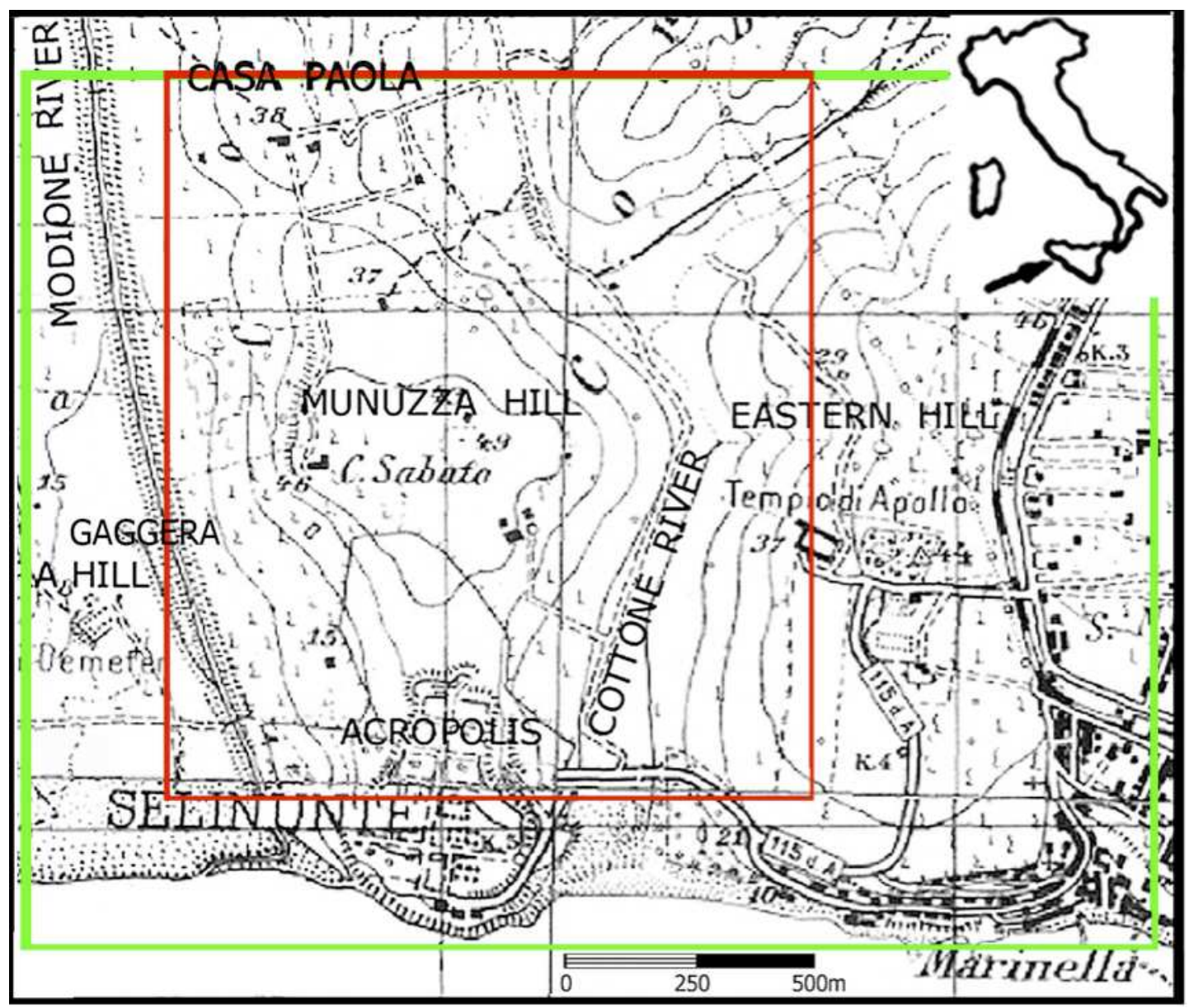

Fig. 1. Topographic map of the archaeological Park of Selinunte. The location of the study area within the Italian context is indicated on the top right. The green square highlights the extent of the original image, while the red one represents the resampled image in terms of spatial extension in order to concentrate attention on the statistical information regarding the investigated area. 


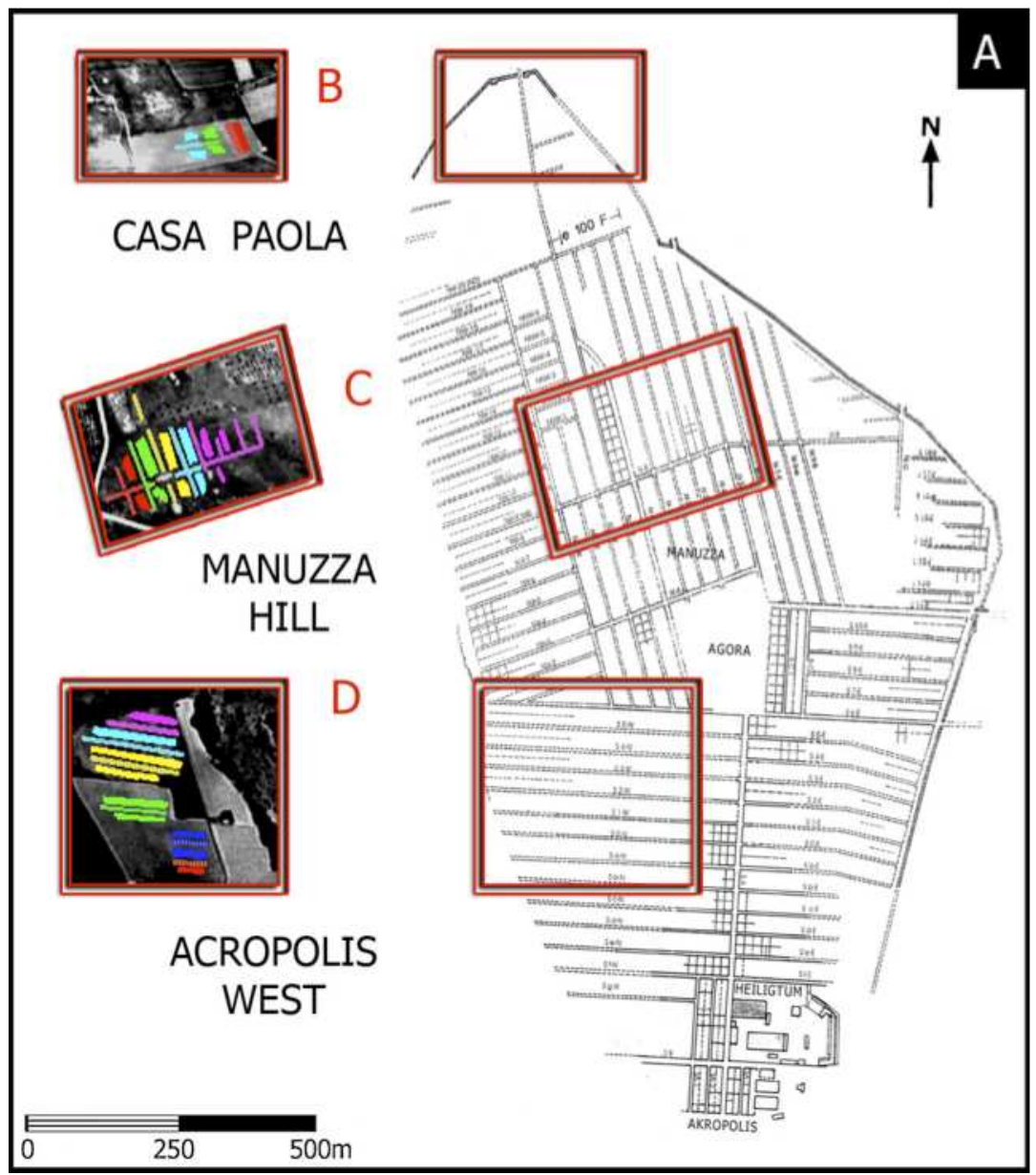

Fig. 2. The urban street network reconstruction performed by Mertens [44], on the right (A). The three red square indicate the location of the three archaeological areas of investigation: Casa Paola (B), Manuzza Hill (C) and Acropolis West (D). On the left, the MIVIS portion image of each archaeological area, depicted in grey scale, partly covers by groups of masks. The elements of each group of masks are depicted with identical colous. One or two masks enclose the areas over the buried archaeological structures, and the other covers the area surrounding the buried structures, to distinguish the area over the buried structures from those surrounding the buried structures grey stripes were superimposed. Figure $2 \mathrm{D}$ which refers to Acropolis West shows 6 groups of masks, each groups of masks is depicted in a different colour, figure 2 C which refers to Manuzza Hill shows 5 groups of masks and figure 2 B which refers to Casa Paola shows 3 groups of masks. 


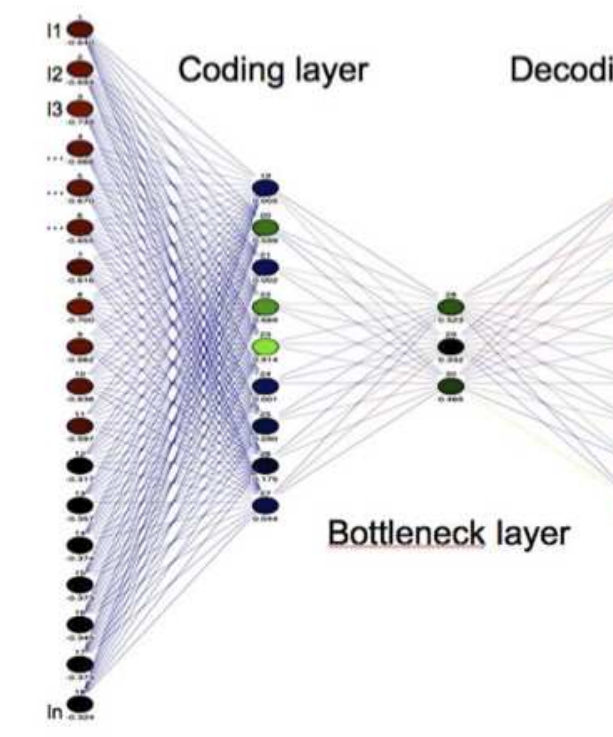

Input layer

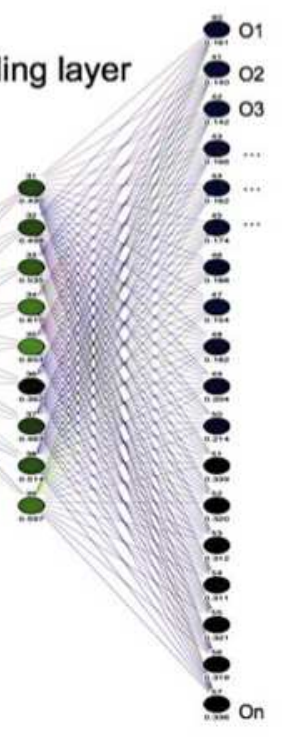

Output layer

Fig. 3. Auto-associative neural networks scheme used for feature reduction.

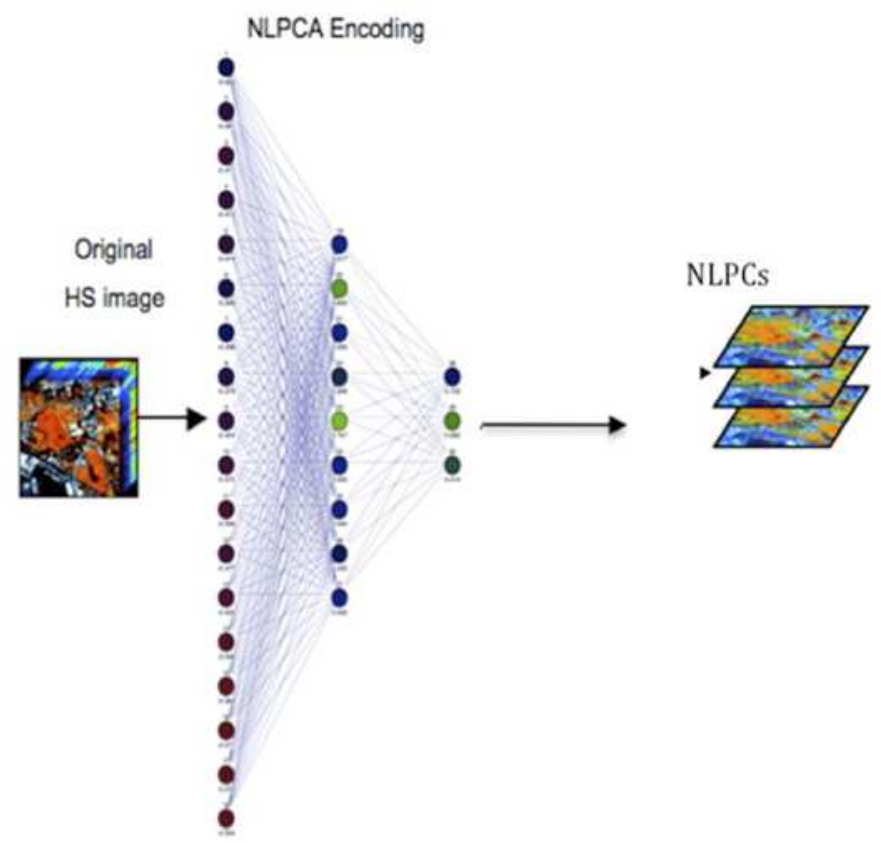

Fig. 4. AANN subnet performing the encode function. 


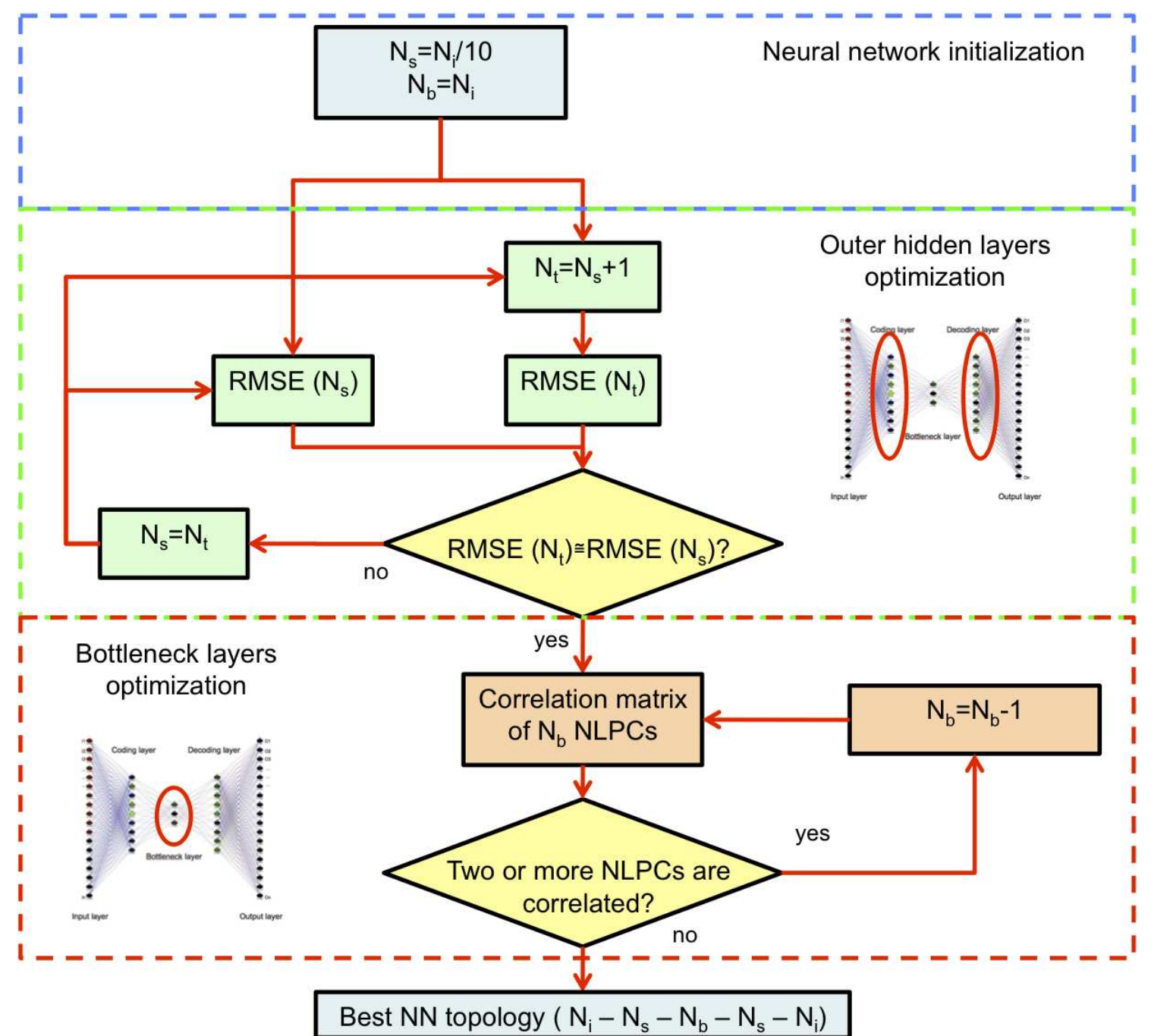

Fig. 5. Complete flowchart describing the optimization of the topology of the AANN. $N_{i}, N_{s}$ and $N_{b}$ represent the number of nodes in the input/output, in the outer hidden layers and in the bottleneck layer, respectively. 


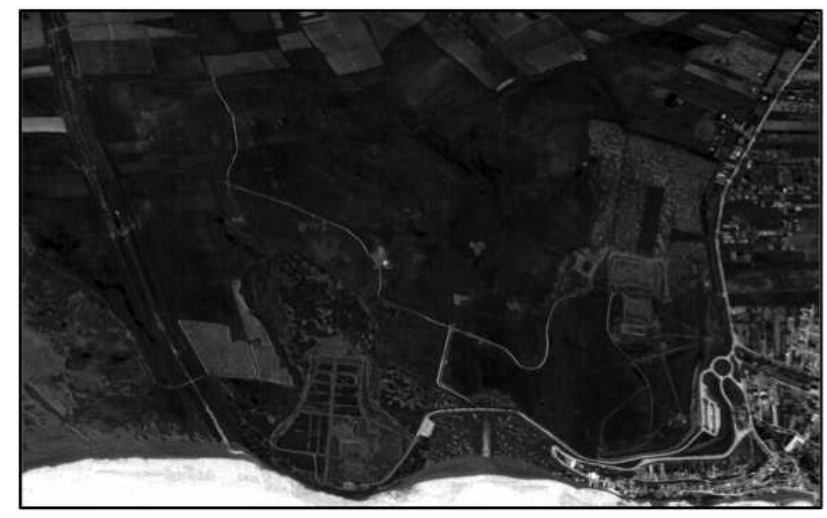

a)

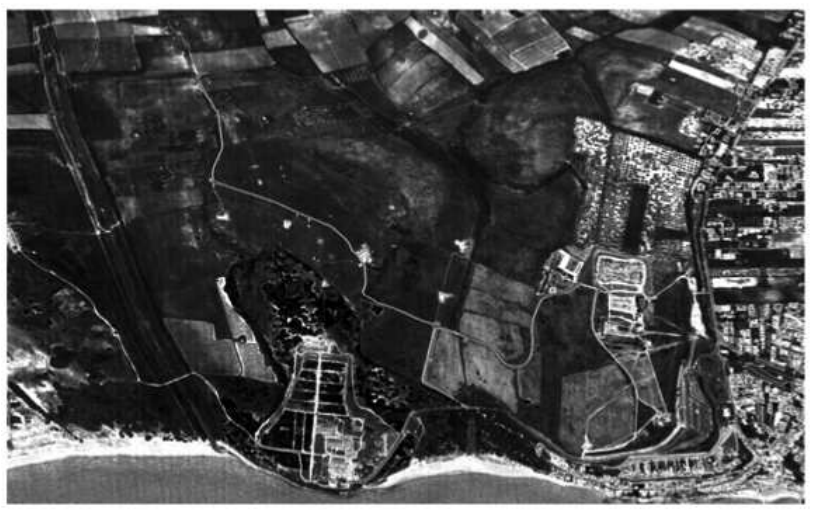

c)

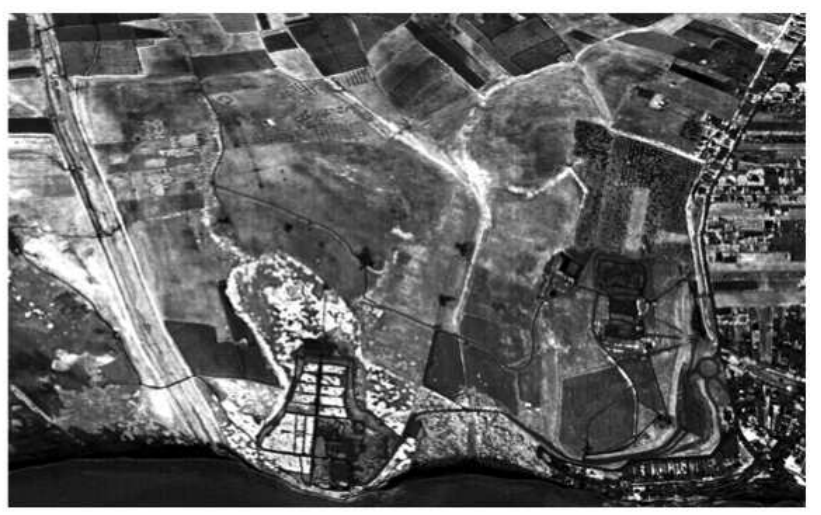

b)

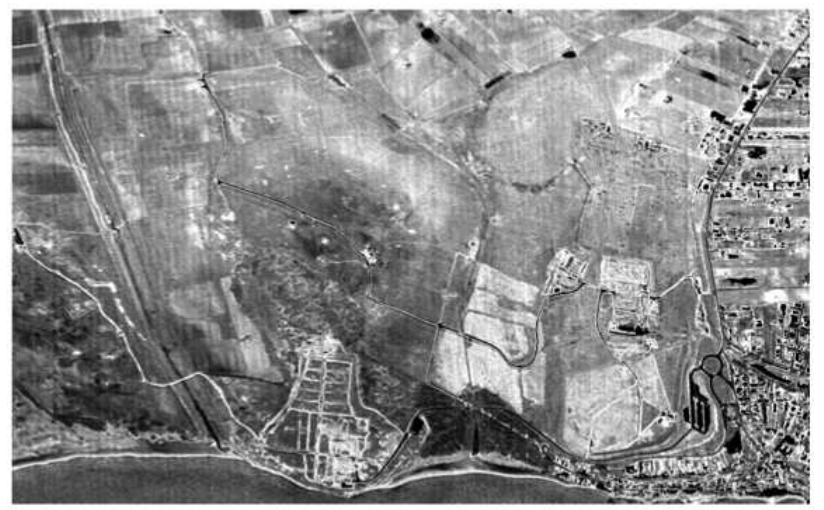

a)

Fig. 6. 4 nonlinear components highlighting: a) water, b) vegetation, c) sand and d) gravel. 


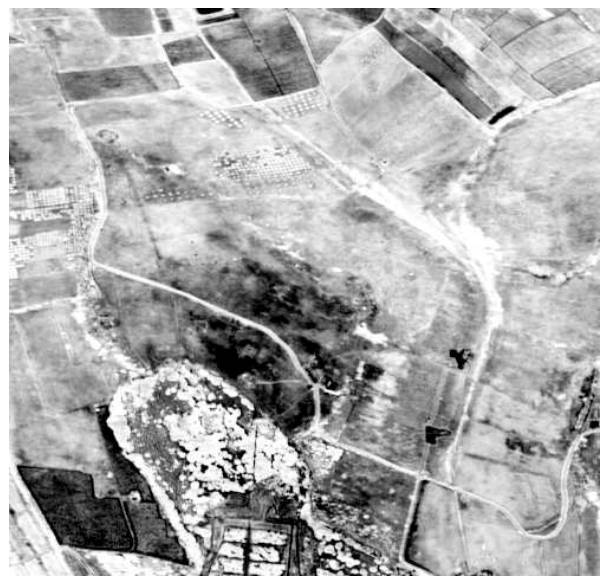

(a) Component 1

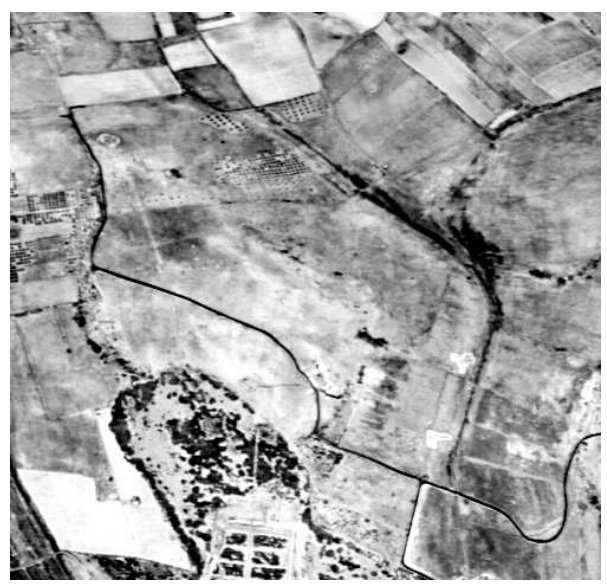

(c) Component 3

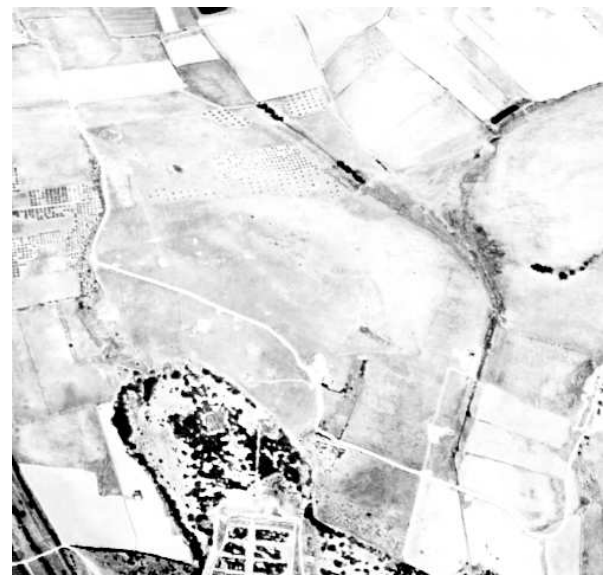

(b) Component 2

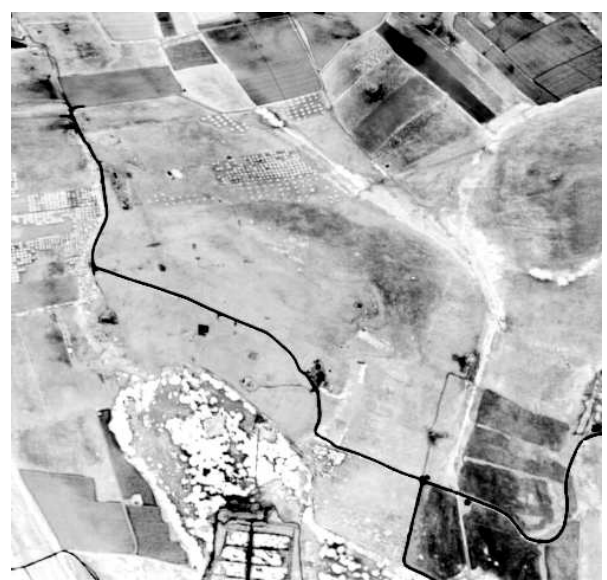

(d) Component 6

Fig. 7. Four NLPCs obtained from the original 102 bands MIVIS image, highlighting the buried road structures 


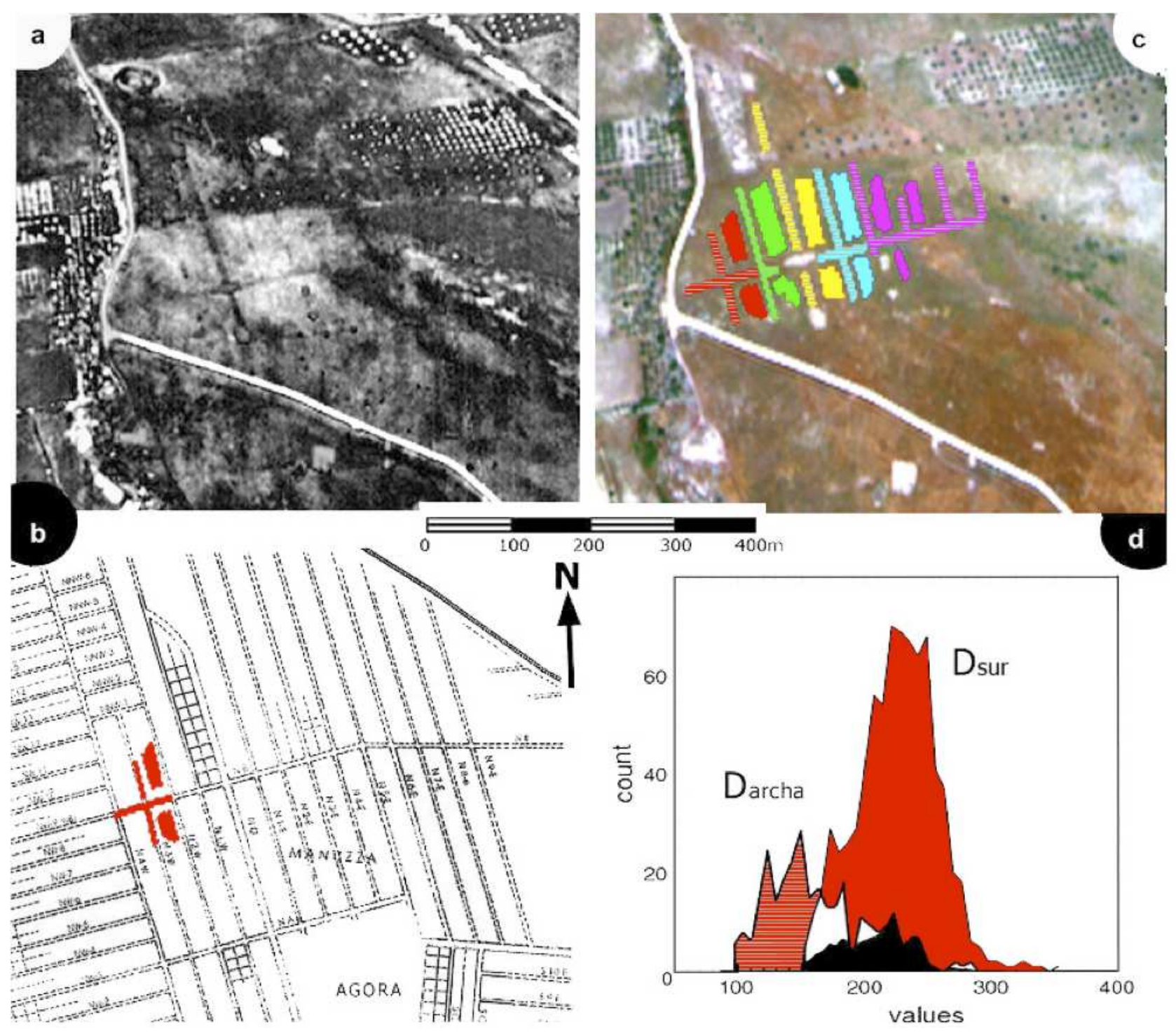

Fig. 8. The Archaeological area of Manuzza Hill highlighted a) in a portion of a MIVIS image, c) in a portion of a MIVIS image with superimposed polygons referring to the 5 groups of masks selected in Manuzza Hill depicted in different colors. c) shows 5 groups of masks selected in Manuzza Hill, the mask covering the buried archaeological structures (archa) are indicated using grey stripes compared to the masks referring to surrounding of the buried structures (sur); depicted in the same color. (b) in a section of the Archaeological sketch map drawn by Mertens [44] covered by a red group of masks, $d$ ) illustrates frequency distributions of the areas covering buried archaeological structures $\left(D_{\text {archa }}\right)$ and the surrounding areas $\left(D_{\text {sur }}\right)$ related to a red group of masks in $\left.c\right)$; the convolution product of the two distributions, represented by SI, is shown in black. 


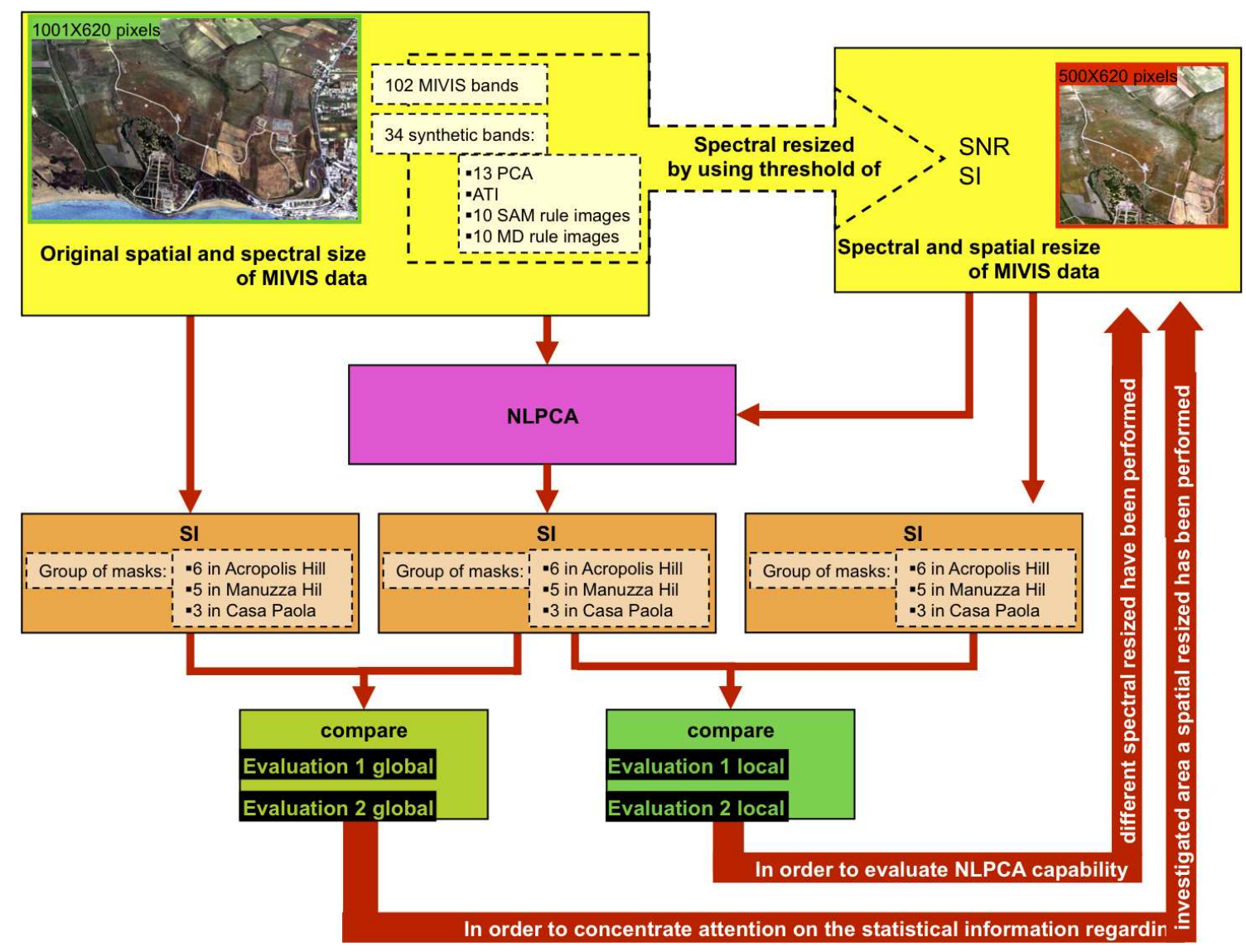

Fig. 9. Flowchart of the process carried out to evaluate the potentiality of NLPCA to produce features able to emphasize the anomalies related to the presence of buried structures. The two RGB images are referred to the original spatial size of the MIVIS data (left) and the resized one (right).
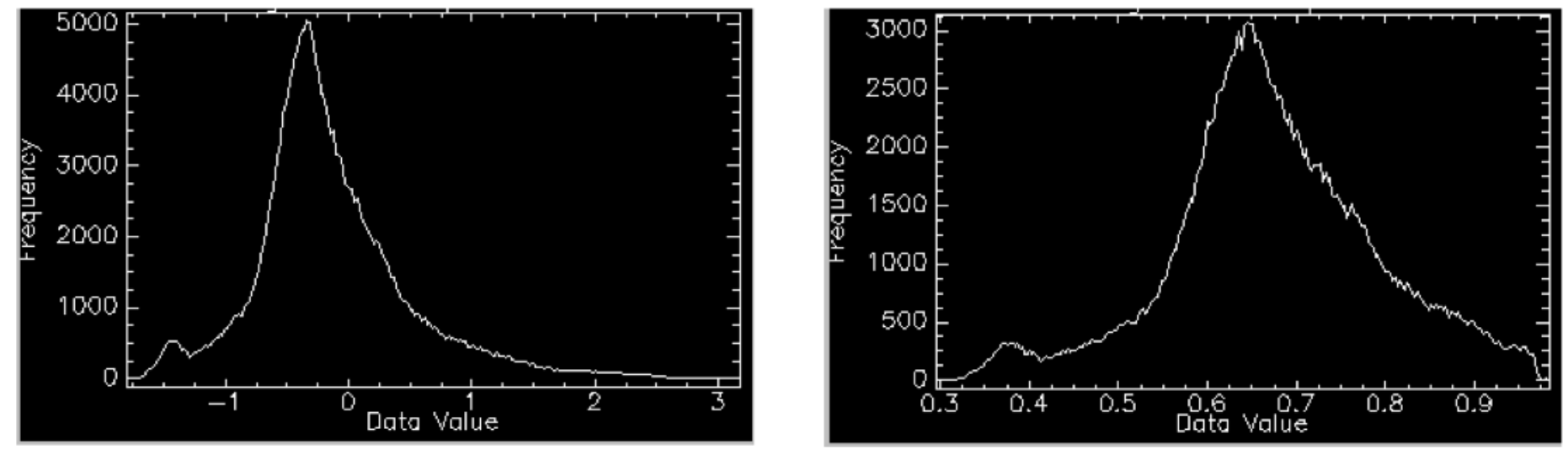

Fig. 10. Comparison of the histograms of the components 7 of the 32 bands image, obtained with a linear activation function (left) and a sigmoid one (right). 